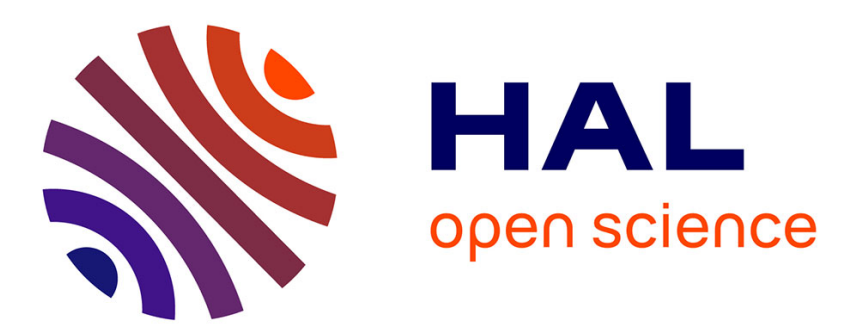

\title{
A soft dynamic programming approach for on-line aircraft 4D-trajectory optimization
}

Patrick Hagelauer, Felix Mora-Camino

\section{To cite this version:}

Patrick Hagelauer, Felix Mora-Camino. A soft dynamic programming approach for on-line aircraft 4D-trajectory optimization. European Journal of Operational Research, 1998, 107 (1), pp 87-95. 10.1016/S0377-2217(97)00221-X . hal-01021633

\section{HAL Id: hal-01021633 \\ https://hal-enac.archives-ouvertes.fr/hal-01021633}

Submitted on 10 Jul 2014

HAL is a multi-disciplinary open access archive for the deposit and dissemination of scientific research documents, whether they are published or not. The documents may come from teaching and research institutions in France or abroad, or from public or private research centers.
L'archive ouverte pluridisciplinaire HAL, est destinée au dépôt et à la diffusion de documents scientifiques de niveau recherche, publiés ou non, émanant des établissements d'enseignement et de recherche français ou étrangers, des laboratoires publics ou privés. 


\title{
A Soft Dynamic Programming Approach for On-Line Aircraft 4D Trajectory Optimization
}

\author{
Patrick Hagelauer *, Felix Mora-Camino ${ }^{+}$ \\ LAAS du CNRS, 7, Avenue du Colonel Roche, \\ 31077 Toulouse, France
}

\begin{abstract}
During the last decade, Flight Management Systems have been introduced on-board modern aircraft to reduce operational costs and flight profiles have been optimized in order to minimize fuel and time related costs. Today, the integration of next generation FMS's in the future air traffic management environment requires the development of new capabilities and among them, 4D optimal trajectory generation has become mandatory.

This paper presents a method based on Soft Dynamic Programming (SDP) to generate on-line optimal 4D trajectories in the presence of multiple time constraints. Soft Computing techniques are introduced to improve the dynamic programming oriented optimization process by on-line selection of the search space and by cutting down computation time in repetitive performance
evaluations.
\end{abstract}

Keywords : Dynamic programming; Optimization; Aircraft trajectory

\section{Introduction}

In the future air traffic management (ATM) environment, precise time control of aircraft flight trajectories is expected to provide significant increase in capacity while maintaining the present level of safety. This requires the development of new capabilities for next generation Flight Management Systems (FMS) among which 4D flyable trajectory generation, meeting Air Traffic Control (ATC) constraints, will play an important role. These constraints are typically altitude or speed constraints at specific waypoints of the flight plan (figure 1). Recently, time constraints have been introduced to increase capacity and reduce delays. More particularly, the efficiency of the Hub and Spoke network structure, which has becn adopted by many airlines, is related to the ability to meet tight arrival time constraints and significant savings can be expected by generating on-line minimum cost 4D flight trajectories.

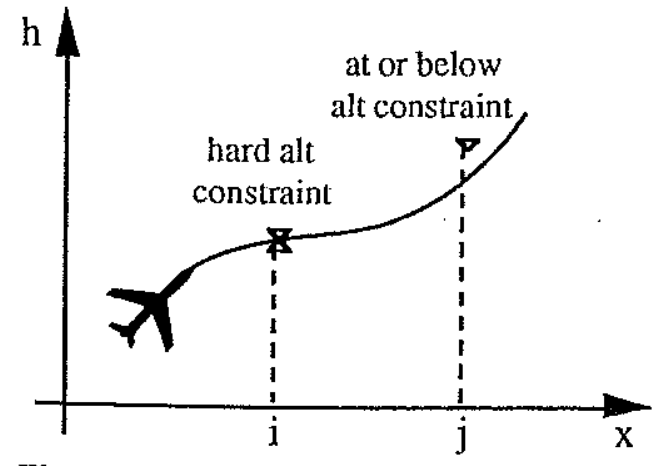

Figure 1 : Aircraft trajectory and constraints

\footnotetext{
* Also Avionics Department, AEROSPATIALE, Toulouse, France (email : patrick.hagelauer@avions.aerospatiale.fr) + Also Air Transportation Department, ENAC, Toulouse, France (e-mail : mora@laas.fr)
}

However the generation of $4 \mathrm{D}$ optimal trajectories within the aircraft performance limitations and satisfying the different ATC constraints is a very delicate problem. Already $4 \mathrm{D}$ trajectories allowing the control of a unique crossing time (AT-type time constraints) at a particular waypoint of the flight plan is available on-board modern long range aircraft (Liden 1994). However, existing solutions do not deal efficiently with this problem. Furthermore, current systems are unable today to deal with multiple time constraints or with more sophisticated time windows such as AT OR BEFORE or AT OR AFTER constraints.

The general 4D trajectory optimization problem can be formulated as an optimal control problem. This approach has been studicd extensively over the past twenty years (Williams and Knox 1991). However, realistic path constraints as imposed by ATC have not been considered in these analysises which have remained far too theoretical.

More recently, mathematical programming approaches have been considered and have proven to be cffective in dcaling with the different constraints (Hargraves and Paris 1987, Betts and Cramer 1995). However, these algorithms use gradient information for the search of a local optimum. As pointed out in most of these studics, the realistic model of an aerospace vehicle typically consists of tabulated acrodynamic and propulsion data and smoothing techniques need to be introduced. Howcver, smoothing data without changing the physical meaning remains a difficult problem.

In this paper, a discrete formulation of the problem is proposed and the corresponding optimal control problem is solved in a (non-gradient) forward dynamic programming framework. The global optimum is achieved and the different constraints are treated directly by search space restriction. Heuristics based on aircraft performance limitations and expert knowledge are introduced to limil the size of the search space. Computation time is further reduced by the use of neural networks to compute the costs associalcd to each decision step in the scarch process. This 
approach leads to the concept of Soft. Dynamic Programming (SDP) that could be introduced, as a practical solution, in future Flight Management Systems.

\section{Mathematical Formulation of the Flight Trajectory Optimization Problem}

\subsection{Flight Trajectory Optimization Problem}

\section{Aircraft Equations of Motion}

Starting with a point-mass model, and assuming small flight path angle and no vertical acceleration, motion in the vertical plane is described by the following dynamics :

$$
\begin{aligned}
& \dot{\mathrm{x}}=\left(\mathrm{V}+\mathrm{V}_{\mathrm{W}}\right) \cos \gamma \\
& \dot{\mathrm{h}}=\mathrm{V} \sin \gamma \\
& \dot{\mathrm{m}}=-\mathrm{f}(\mathrm{T}, \mathrm{h}, \mathrm{V})
\end{aligned}
$$

where $\mathrm{x}$ is the range, $\mathrm{h}$ the altitude, $\mathrm{V}$ the airspeed, $\mathrm{V}_{W}$ the horizontal component of wind speed, $m$ the mass, $f$ the fuel flow rate, $T$ the thrust and $\gamma$ the flight path angle.

The airplane model also involves the evaluation of drag $D(V, h, m)$, lift $L(V, h, m)$ and thrust $T(V, h, m)$ represented on figure 2.

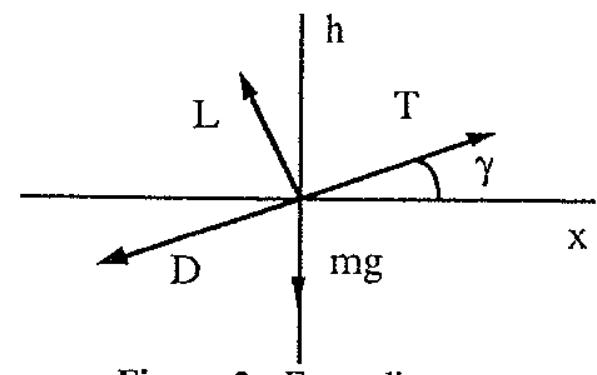

Figure 2 : Force diagram

In steady flight conditions, these variables satisfy the static aircraft equilibrium equations :

$$
\begin{aligned}
& \mathrm{L}-\mathrm{mg} \cos \gamma=0 \\
& \mathrm{~T}-\mathrm{D}-\mathrm{mg} \sin \gamma=0
\end{aligned}
$$

\section{Performance Index}

The cost function considered in the optimization problem represents the Direct Operating Cost (DOC). The DOC is defined as the cost of the consumed fuel plus other costs related to flight time and is written :

$$
\mathrm{DOC}=\mathrm{FUEL}+\mathrm{CI} * \mathrm{TIME}
$$

where FUEL and TIME represent fuel burn and flight time over a given ground distance. $\mathrm{Cl}$, the so-called Cost Index, is a fuel equivalent cost for time. It is a selectable parameter which can be used by the airlines to balance fuel and time costs.

The performance index to be minimized is the cost of flight for a given ground distance which can be written in the integral form as:

$$
J=\int_{t_{i}}^{t_{t}}(f+C I) d t
$$

However, since time is a space related constraint variable (time constraints are defined at specific points of the flight plan, see figure 1), while the distance to go is a true independent variable, this performance index can be rewritten as :

$$
J=\int_{x_{i}}^{x_{f}} \frac{(I+C I)}{\left(V+V_{w}\right) \cos \gamma} d x
$$

where $\left[\left(V+V_{W}\right) \cos \gamma\right]$ represents aircraft ground specd.

\subsection{General Fornulation}

A standard formulation of this 4D trajectory optimization problem can be proposed as a constrained optimal control problem :

$$
\min _{u(x)} \int_{x_{i}}^{x_{1}} L[y(x), u(x), x] d x
$$

under the following constraints :

Flight dynamics :

$$
\frac{d y}{d x}=f[y(x), u(x), x]
$$

Range constraints on the state variable vector:

$$
y_{L}[y(x), x] \leq y(x) \leq y_{H}[y(x), x]
$$

Range constraints on the control variable vector :

$$
u_{L}[y(x), x] \leq u(x) \leq u_{H}[y(x), x]
$$

In addition, the solution must satisfy discrete constraints on the state variables as shown on figure 1 :

$$
\begin{aligned}
& N\left[y\left(x_{i}\right), x_{i}\right]=0 \\
& M\left[y\left(x_{j}\right), x_{j}\right] \leq 0
\end{aligned}
$$

\subsection{Cruise Phase Optimization}

For long range aircraft, the cruise phase constitutes the main part of the flight and its optimization induces the major part of the potential cost Savings. Current Flight Management Systems compute an optimum altitude bascd on gross weight and spced schedule for a given aircraft. In a steady atmosphere, the optimum altitude incrcases theorelically nearly linearly with distance as fucl is burned off (Liden 1992a). In the presence of winds, however, the optimal flight level may suffer very large variations (Liden 1992b). Aircraft cruise flight is usually restricted to specific flight levels assigned by ATC and the problem of optimizing discrete shifts between flight levels during cruise is economically worthwhile.

In the proposed approach, transitions from one flight level to another are treated as discrele events in the cruise optimization problem. This assumption is justificd by the fact that steps are generally in small numbers, typically 2 or 3 for long flights, and only represent a very small portion of the total cruise phase. With this assumption, altitude evolutions arc restricted to level flight and the altitude state variable can only take discrete values. When time constraints are introduced in the cruise phase, the FMS must compute a new speed profile which will, in turn, have an effect on the optimal altitude shift points.

The 4D cruise optimization problem therefore consists in determining the optimal speed schedulc and associated step points satisfying aircraft limitations, operational constraints and the different time constraints.

Although aircraft flight dynamics are considerably simplified for cruise, the represcntation of the system 
involves both continuous (speed) and discrete (altitude) states which is typical of hybrid-state systems. Because of the discontinuous nature of the hybrid-state system, difficulties arise when classical optimization algorithms are used (Lu et al. 1993). To overcome these difficulties, the following section describes a Soft Dynamic Programming approach which generates optimized 4D trajectories whilc overcoming the limitations of previous approaches.

\section{Dynamic Programming Approach}

\subsection{General Mathematical Formulation}

The basic approach for solving the optimal control problem using dynamic programming (DP) consists in discretizing the problem and applying the classical Beliman principle of optimality.

The independent variable is written as

$$
\mathrm{x}_{\mathrm{k}}=\mathrm{x}_{0}+\mathrm{k} \Delta \mathrm{x} \quad \mathrm{k} \in\left[0, \ldots, \mathrm{N}_{\mathrm{x}}\right]
$$

the state and control variable vectors are :

$$
\begin{aligned}
& y(k)=y\left(x_{k}\right) \\
& u(k)=u\left(x_{k}\right)
\end{aligned}
$$

the discretized state equations then become :

$$
y(k+1)=f[y(k), u(k), k] \quad k \in\left[0, \ldots, N_{X}-1\right]
$$

and the performance index :

$$
J=\sum_{k=0}^{N_{x}-1} L[y(x), u(x), x]
$$

The bounds on the state or control variables, as well as the different constraints, are treated directly by state space and control space restrictions at each decision step :

$$
\begin{aligned}
& y(k) \in \mathbf{Y}(k)=\left\{\mathbf{y}_{1}(k), \ldots, \mathbf{y}_{N y}(k)\right\} \quad k \in\left[0, \ldots, N_{X}\right] \\
& \mathbf{u}(k) \in U(k)=\left\{\mathbf{u}_{1}(k), \ldots, \mathbf{y}_{N v}(k)\right\} \quad k \in\left[0, \ldots, N_{X}-1\right]
\end{aligned}
$$

At each step $\mathrm{k}$ to $\mathrm{k}+1$, and for every state $\mathrm{y}(\mathrm{k}+1)$, dynamic programming is performed by applying Bellman's principle of optimality :

$$
\begin{aligned}
& I^{*}[y(k+1), k+1]= \\
& \min _{\substack{y_{1}(k) \in Y_{(k)} \\
u_{1}(k) \in U(k)}}\left[I^{*}\left[y_{i}(k), k\right]+L\left[y_{i}(k), u_{i}(k), k\right]\right]
\end{aligned}
$$

where $I^{*}\left[y_{i}(k), k\right]$ represents cost of the optimal path from the initial state to state $y_{i}(k)$.

\subsection{Application To Cruise Phase Optimization}

The discretized equations of motion for cruise flight can be written as :

$$
\begin{aligned}
& \mathrm{t}(\mathrm{k}+1)=\mathrm{t}(\mathrm{k})+\Delta \mathrm{t}(\mathrm{k}) \\
& \mathrm{h}(\mathrm{k}+1)=\mathrm{h}(\mathrm{k})+\Delta \mathrm{h}(\mathrm{k}) \\
& \mathrm{m}(\mathrm{k}+1)=\mathrm{m}(\mathrm{k})-\mathrm{FUEL}[\mathrm{h}(\mathrm{k}), \mathrm{m}(\mathrm{k}), \mathrm{M}(\mathrm{k})]
\end{aligned}
$$

When time constraints are introduced (4D optimization), the performance index can be simplified. Flight time is a space related constraint and can therefore be eliminated from the performance index which reduces to

$$
\operatorname{COST}=\mathrm{FUEL}
$$

For $4 \mathrm{D}$ cruise phase optimization, the performance index is therefore:

$$
J=\sum_{k=0}^{N_{x}{ }^{-1}} F U E L[h(k), m(k), M(k)]
$$

where $M(k)=$ Mach number at each siep

FUEL[h(k),m(k),M(k)] = fuel burn from stcp $k$ to step $k+1$ (which depends on altitude, aircraft weight and Mach number over each step)

The dynamic programming approach for cruise optimization is presented on figure 3 .

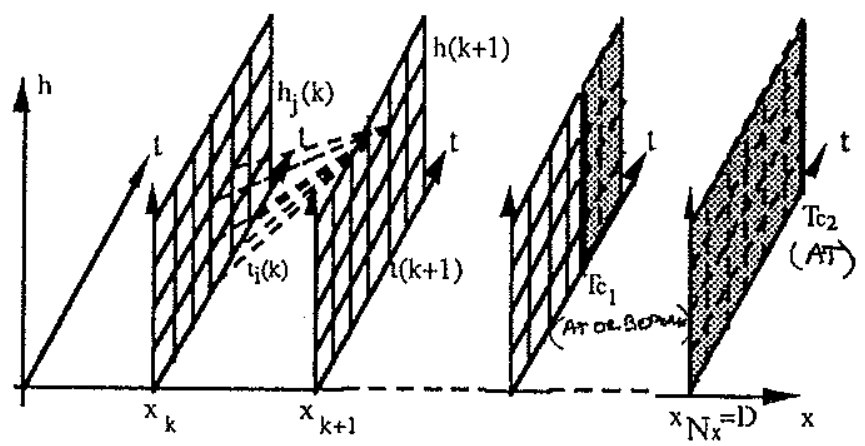

Figure 3 : Search space and restrictions (dashed areas) for $4 \mathrm{D}$ dynamic programming

The dynamic programming formula becomes :

$$
\begin{aligned}
& I^{*}\left[t(k+1), h(k+1), x_{k+1}\right]= \\
& \min _{\substack{\left(t_{j}(k), h_{j}(k)\right) \in T(k) \times I I(k) \\
\Delta h(k), M_{i j}(k) \in V(k)}}\left[I^{*}\left[t_{i}(k), h_{j}(k), x_{k}\right]+\right.
\end{aligned}
$$

$$
\text { FUEL } \left.\left[h_{j}(k), m_{i j}(k), M_{i j}(k)\right]\right]
$$

where $\mathbf{H}(k)$ and $\mathbf{T}(k)$ represent the allowable search spacc at each step and FUEL the fuel burn from state $\left[\mathrm{t}_{\mathrm{i}}(\mathrm{k}), \mathrm{h}_{\mathrm{j}}(\mathrm{k}), \mathrm{x}_{\mathrm{k}}\right]$ to $\left[\mathrm{t}(\mathrm{k}+1), \mathrm{h}(\mathrm{k}+1), \mathrm{x}_{\mathrm{k}+1}\right]$.

Figure 3 shows a typical search space for a dynamic programming solution to a $4 \mathrm{D}$ cruise optimization problem in which two time constraints $\mathrm{Tc}_{1}$ and $\mathrm{Tc}_{2}$ are considered. At the last step, the costs of the different solutions satisfying both time constraints are compared. The flight profile with the lowest cost is then retained as the optimal cruise profile and proposed to the pilot. Note that, in this study, dynamic programming is performed in a forward manner since the performance index is state dependent and the final state is not known a priori (final aircraft weight in particular).

\section{Improvement of the DP Solution With Soft Computing Techniques}

Computer based FMS functions should have short time responses to allow their use in real time conditions by the 
pilot: no more than 20 to 30 s for non critical functions on existing FMS's and much less in the future. This is a critical aspect of the problem even if on-board processing power has largely increased over the last decade.

Dynamic programming solution approaches have not been widely used in practice for time critical applications due to the associated computational burden. In cases where it has been used, heuristics have been introduced to reduce the search space and the number of state transitions. However, with the fast evolution of processing capabilities, several well known techniques have bcen recently revisited for their possible application to real timc problems (Williams and Knox 1991). In the present application, computation time is reduced by on-line limitation of the dynamic programming search space and the use, at each decision step, of neural networks for cost evaluations.

\subsection{Search Space Reduction}

Several authors have focused on the design of minimum cost path through a set of predefined nodes. The most classical problem in this class is the travelling salesman problem (TSP) which has been studied extensively. Dumas et al. (1995) have introduced elimination tests which greatly enhance the performance of a dynamic programming approach and the application to the minimization of the total cost for the travelling salesman problem with time windows (TSPTW). In this work, the search space and the number of state transitions are reduced by introducing elimination tests both a priori and during the execution of the algorithm. However, the area of application of the present study enables the introduction of additional heuristics based on operational considerations and the knowledge of aircraft performances and limitations.

The search space is primarily defined by pilot entercd parameters such as considered flight levels during icruise phase, and by state and control variable upper and lower bounds. The different ATC constraints are directly accounted for by limiting the search space to the acceptable states. These are defined by altitude, speed and lime constraints along the flight. The time constraints are either hard crossover time constraints or window type constraints.

Known aircraft performances and limitations associated with the aircraft flight envelope must also be taken into consideration. But, since these limitations are aircraft state dependent, they can only be dynamically determined at each step in the search process.

The combination of these different search space and state transition reduction heuristics improves the computation time of the dynamic programming algorithm. However, further improvements can be achieved by including operational considerations and design enginecr or pilot expert knowledge. Among these considerations, the generally observed slowly varying nature of optimal speed profiles is taken into account to significantly reduce the search space by limiting speed evolutions from one step to another. The introduction of these elimination tests reduccs the computation time of the dynamic programming solution by approximately 5 .

\subsection{Computation Time Reduction Using Neural Networks}

Computation of costs at the different dynamic programming steps essentially breaks down to aircraft fuel burn evaluations. Typically these are computed using aircraft flight dynamics as well as aerodynamic and performance look up tables. These repeatcd cvaluations require an extensive computation effort and may turn the dynamic programming approach incompatible with on board real time requirements. When using current fuel burn models, $90 \%$ of total computation time of the DP algorithm is spent on cost evaluations.

In a preliminary attempt of this study, polynomial approximations of fucl flow computation for level flight were introduced. Howcver, the complex nature of the fuel flow function and the required accuracy werc found to be incompatible with such an approach. Thereforc, a different approach, based on recent soft computing techniques, has been considered. The proposed solution introduces a neural network to perform fuel flow evaluations. It has been shown in previous theoretical work that neural networks can be turned into "universal approximators". Cybenko (1989) and Funahashi (1989) proved that any continuous function can be approximated on a compact set by a neural network with one hidden layer. Furthermore, Hornick, Stinchcombe and White (1989) showed that any measurable function can be approached with such a network. These results, however, do not give any information on the ways of building the network. The general approach therefore consists in a trial and error method which usually delivers acceptable solutions.

In this study, a two layer neural network has been found to be sufficient to provide good fucl flow approximations. In order to reduce the computation time of the simulated neural network, the classical sigmoid activation function has been replaced by a simpler rational function :

$$
f(x)=\frac{x}{|x|+1}
$$

It has then been observed that the replacement of the previous fuel burn computations by a neural network devides the total computation time of the dynamic programming algorithm by approximately 8.5 .

\subsection{Comparison With Existing Solutions}

Both the existing and the Soft Dynamic Programming approaches for $4 \mathrm{D}$ cruise optimization have been simulated on a work station for time response comparisons. Since the problem considered here has extended objectives, it should require much more processing lime. However, the SDP solution contains this by the introduction of the climination tests and other soft computing techniques.

The different solutions have been compared for reduced complexity problems involving a unique hard time constraint at a specific crossover point in the flight plan. In the worst cascs, the SDP solution is found to require three times more computation time than the cxisting methods. Additional heuristics have becn considered to further improve the time response of the SDP solution. A possible restriction of the search space around a constant cruise Mach solution leading to a local dynamic 
programming solution is being cvaluated. Results for this approach are not yet available.

\section{Simulation Results}

Computer simulations have been performed on several case studies to evaluate the performance of the SDP approach for cruise phase optimization. The trajectories were compared with those generated by the existing optimization functions.

\subsection{D Cruise Optimization With a Unique Time Constraint}

Existing FMS profile optimization functions only deal with a unique AT-type time constraint at a specilic waypoint of the flight plan. The optimization algorithms typically seek to adjust the Cost Index to satisfy the required time constraint. The existing solutions define new speed profiles on a frozen altitude profile, therefore they will be referred to here as fixed altitude profile (FAP) solutions. The SDP solution, on the other hand, gencrates a cruise trajectory with a new optimal speed profile and a new associated altitude profile. In addition, the speed profiles generated by the SDP method are not restricted to constant $\mathrm{CI}$ profiles, as they are in the FAP approach.

\section{Case study description}

In the following case study, the SDP solution is compared to the classical FAP solution. In this example, we consider a long range cruise flight with several possible flight levels and a unique time constraint at the end of the cruise phase. Both the FAP and SDP solutions have been simulated on a work station to determine the altitude profiles, speed profiles and associated fuel burn based on the aerodynamic, engine and performance models of an Airbus A340.

In this case study, we have considered a $6000 \mathrm{NM}$ long cruise flight with no wind at all flight levels. The other data for this example are as follows and presented in figure 4

Possible cruise flight levels : FL310, FL350 and FL390

Aircraft weight at cruise start : 250 tons

Before introduction of the time constraint, at a distance of $6000 \mathrm{NM}$, the step points were determined on the ground for no wind conditions and a Cost Index of 50

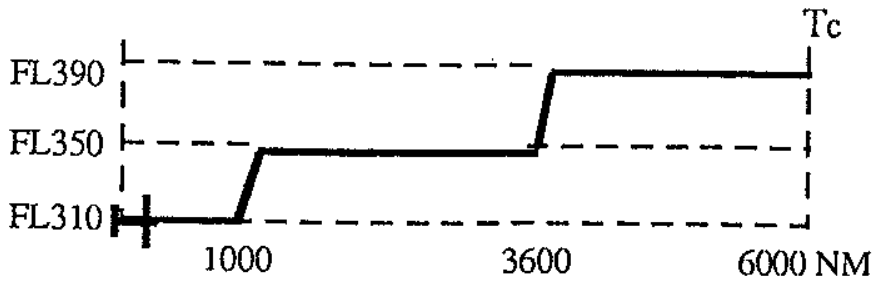

Figure 4 : Case study description

\section{Step point location}

On figure 5 , cruise distance is represented along the horizontal axis while the possible values of the time constraint are given along the vertical axis. The curves represent, for the different values of the time constraint, the Iocation of the stcp points gencrated by the FAP and SDP solutions.

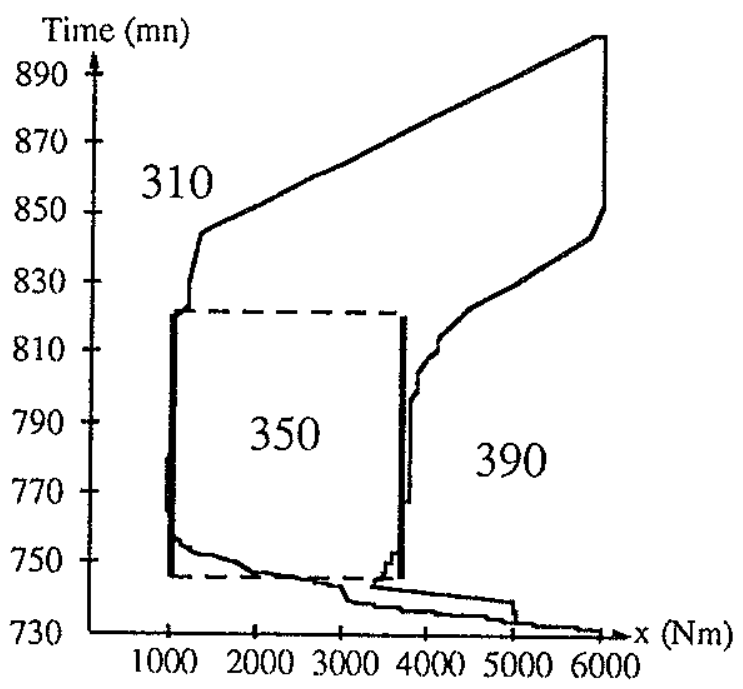

Figure 5 : Step point locations for different time constraints

For the classical FAP algorithm, the step points are frozen and correspond to the initial assumptions of no wind flight conditions and a Cost Index value of 50 . The step point locations are represented on figure 5 by two vertical bold lines. The achievable time constraints are determined by using the range of possible Cost Index values [100,999] which determines minimum and maximum speed schedules. With the FAP approach, time constraints between $747 \mathrm{mn}$ and $817 \mathrm{mn}$ can be satisfied. This time window is defined by two horizontal dashed lines on figure 5 .

The location of the step points generated by the SDP solution are also represented for all achicvable time constraints. In the time window $[757 \mathrm{mn}, 800 \mathrm{mn}]$, both solutions define comparable step points. Outside this time window, the step points are located diffcrently. For a time constraint of $747 \mathrm{mn}$, representing the lower range of the FAP approach, the SDP solution defines a first step point that is located about $1500 \mathrm{NM}$ further. It also appcars that the additional degrees of frecdom of the SDP approach provides a much larger achievable time window as can be seen on figure 5 .

\section{Fuel burn}

Figure 6 illustrates the cruise fucl burn corresponding to the solutions for the different achicvable time constraints. In figure 6 , time constraints are represented on the horizontal axis and cruise fuel consumption on the vertical axis. 


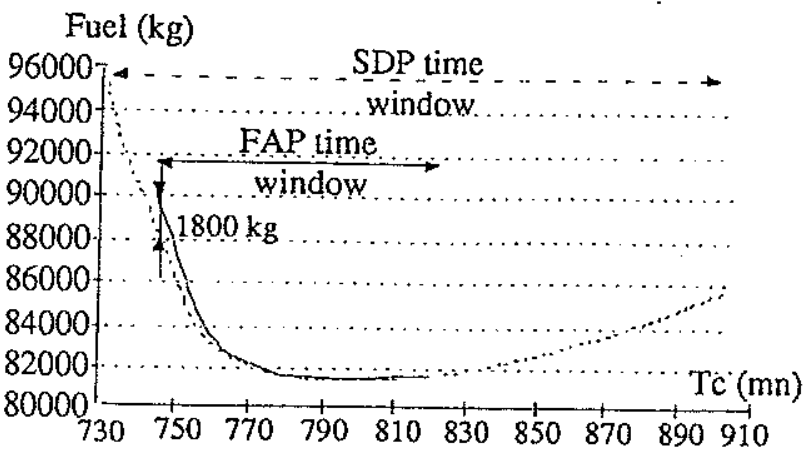

Figure 6 : Cruise fuel burn for the classical and SDP solutions

In the time frame $[757 \mathrm{mn} ; 800 \mathrm{mn}]$, where both solutions define the same step points, the fuel burn is similar. However, outside this time window, fuel consumption performances can be very different : For a time constraint of $747 \mathrm{mn}$ for example, the fuel saving associated with the shift of the step point locations is approximately of $1800 \mathrm{~kg}$ which represents a total cruise fuel saving of $2 \%$.

\subsection{D Cruise Optimization With Multiple Time Constraints}

The performed computer simulations have demonstrated the feasability of the SPD approach in dealing with $4 D$ cruise optimization problems with multiple time constraints. The SDP approach is able to deal efficiently with several time constraints of different types as long as they are compatible, i.e. achievable within the flight envelope of the aircraft.

The previous cruise flight is considered but two time constraints ( $\mathrm{Tc}_{1}$ at $3000 \mathrm{NM}$ and $\mathrm{Tc} 2$ at $6000 \mathrm{NM}$ ) are now introduced :

$$
\begin{array}{lll}
\mathrm{Tc}_{1}: \text { AT OR BEFORE } & 395 \mathrm{mn} & \left(-395^{\prime} \mathrm{mn}\right) \\
\mathrm{Tc}_{2}: \mathrm{AT} & 770 \mathrm{mn} & (=770 \mathrm{mn})
\end{array}
$$

Figures 7 shows the Mach profile generated by the existing FAP solution. Since the existing approach can only deal with one constraint at a time (and only AT-type time constraints), the solution is generated by applying the FAP method twice in succession.

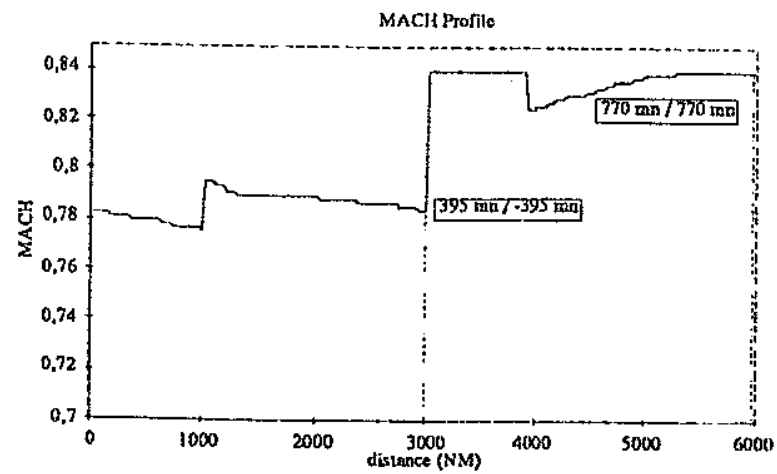

Figure 7 : FAP solution for multiple time constraint problems
Figure 8 shows the Mach profile generated by the SDP approach.

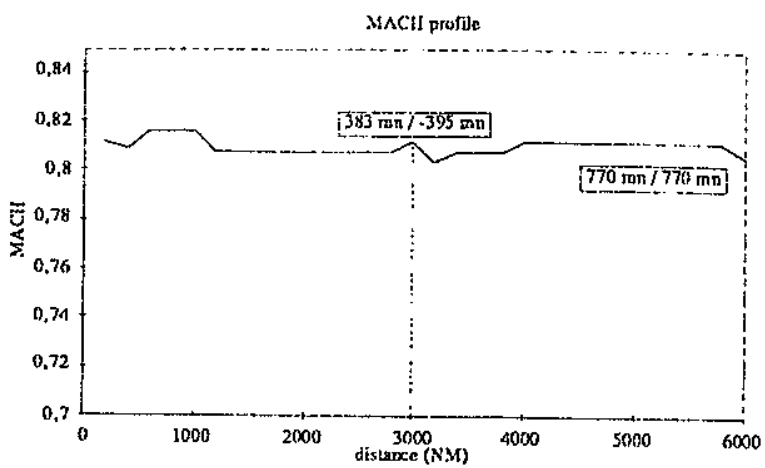

Figure 8: SDP solution for multiple time constrain problems

The time constraints are such that the altitude profile is unchanged for both solutions, and is therefore as presented on figure 4. However, the SDP approach takes full taken advantage of the characteristics of the first time constraint (AT OR BEFORE) and the predicted passing time at $\mathrm{Tc}_{1}$ is $12 \mathrm{mn}$ earlier than wich the FAP solution.

The resulting fuel burn in both cases is:

$$
\begin{aligned}
& \text { FAP solution : } 85645 \mathrm{~kg} \\
& \text { SDP solution : } 82169 \mathrm{~kg}
\end{aligned}
$$

The fuel saving of the global SDP approach, over the classical FAP solution used twice in succession, is of approximately 3.5 tons. This is considerable and could justify the implementation of the more complex SDP solution in future Flight Management Systems as such time constraints become more widely used by Air Traffic Control.

\section{Conclusions}

In this study, the on-line cruise optimization problem is solved using a Soft Dynamic Programming (SDP) approach. The dynamic programming formulation significantly improves the optimum trajectory generation capabilities of existing Flight Management Systems. It has been shown that relevant fuel savings can be obtained, over existing FMS optimization functions, for 4D optimization problems with a unique hard time constraint. Furthermore, this new approach provides extended capabilities for $4 \mathrm{D}$ trajectory generation: It performs $4 \mathrm{D}$ cruise optimization for multiple time constraint problems with the possibility of including "window type" constraints.

Although dynamic programming is usually considered as a time consuming technique, here processing times have been cut down to acceptable levels by the use of operational limitations and expert knowledige to reduce the size of the search space and the number of statc transitions. Furthcrmore, neural networks have been introduced for fuel burn calculations at each decision step which divides compulation time by about 8.5 over current fucl burn evaluations. Increased processing power in next gencration Flight Management Computers should further divide computation times by approximately 5. The SDP approach 
therefore seems to provide a solution for on-line optimization in next generation Flight Management Systems.

\section{References}

BETTS, J.T., CRAMER, E.J. 1995 Application of Direct Transcription to Commercial Aircraft Trajectory Optimization. J.Guidance, Control and Dynamics 18, 151-159

CARDALIAGUET, P., EUVRARD， G. 1992 Approximation of a Function and its Derivatives with a Neural Network. Neural Networks, 5, 207-217

CHAKRAVARTY, A. 1985 Four-Dimensionam FuelOptimal Guidance in the Presence of Winds. J.Guidance, Control and Dynamics, 8, 16-22

CYBENKO, G. 1989 Approximation by Superpositions of a Sigmoidal Function. Mathematical Control Signals Systems, 2, 303-314

DUMAS Y., DESROSIERS J., GELINAS E., SOLOMON M. 1995 An Optimal Algorithm for the Traveling Salesman Problem with Time Windows. Opns. Res. 43, 367-371

FUNAHASHI, K. 1989 On the Approximate Realization of Continuous Mappings by Neural Networks. Neural Networks, 2, 183-192

HARGRAVES, C.R. PARIS, S.W., 1987 Direct Trajectory Optimization Using Nonlinear Programming and Collocation. .Guidance, Control and Dynamics, 10, 338-342.

HORNIK, K., STINCHCOMBE, M., \& WHITE, H. 1989 Multilayer Feedforward Networks are Universal pproximators. Neural Networks, 2, 359-366

LIDEN, S.P. 1992a Oplimum Cruise in the Presence of Winds. AlAAIIEEE 11th Digital Avionics Systems Conference, Seattle W.A., 254-261

LIDEN, S.P. 1992b Optimum 4D Guidance for Long Flights. AIAAIIEEE 11th Digital Avionics Systems Conference, Seatle W.A., 262-267

LIDEN, S.P. 1994 The Evolution of Flight Management Systems. AIAA/IEEE Digital Avionics Systems Conference, 157-169

LU J., LIAO L., NERODE A. AND TAYLOR J.H. 1993 Optimal Control of Systems with Continuous and Discrete States. Proceeding of the 30th Conference of Decision and Control, San Antonio, Texas, 22922297

WILLIAMS D.H., KNOX C.E. 1991 4D Descent Trajectory Generation Techniques Under Realistic Operating Conditions. $A G A R D-A G-301,2,25-1$ - 25 $-22$ 